\title{
Development of a Real-Time Model of the Occupancy of Short-Term Parking Zones
}

\author{
Reinhard Hössinger • Peter Widhalm • Michael Ulm • \\ Klaus Heimbuchner • Eike Wolf • Roland Apel • \\ Tina Uhlmann
}

Received: 20 March 2013 /Revised: 11 September 2013 / Accepted: 7 October 2013 / Published online: 23 November 2013

(C) The Author(s) 2013. This article is published with open access at Springerlink.com

\begin{abstract}
The lack of reliable information about the occupancy of on-street parking places in the inner districts of large cities causes an unnecessarily high amount of parking search traffic. Previous attempts to solve the problem rely on accurate information systems that navigate drivers to the next available parking space. They have failed due to high costs for roadside sensors and are also controversial, because they indirectly support car use. A service that informs road users early about the situation at the destination would support a shift towards public transport modes and reduce parking search traffic particularly at times of unexpectedly high parking pressure. The real-time occupancy model presented in this article does not aim to indicate the occupancy of single parking lots, but to provide a sufficiently accurate description and reliable prediction of the occupancy at the destination. Three existing realtime indicators were tested for their predictive power: (i) location data of mobile-phone parking; (ii) counts of car parks in the vicinity; and (iii) traffic flow volumes. Experimental results indicated that models using mobile-phone parking data have the potential to improve predictions of the occupancy rate by detecting exceptional deviations from the average day curve.
\end{abstract}

R. Hössinger · T. Uhlmann $(\bowtie)$

Institute for Transport Studies, BOKU, Vienna, Austria

e-mail: tina.uhlmann@boku.ac.at

P. Widhalm • M. Ulm

Austrian Institute of Technology, Vienna, Austria

K. Heimbuchner

Heimbuchner consulting GmbH, Vienna, Austria

E. Wolf

Ing. Dr. iur. Eike Wolf, Vienna, Austria

R. Apel

ITP Unternehmensberatung GmbH, Vienna, Austria
Keywords ITS · Telematics · Parking management $\cdot$ Short term parking $\cdot$ Mobile phone parking $\cdot$ Real-time occupancy model

\section{Introduction}

Driver assistance systems (DAS) became very popular in recent years. The automobile industry and academic researchers spend much effort to develop such systems [16]. They can detect certain driving situations and provide car drivers with real-time information on different aspects such as travel time [1] and parking facilities. The parking process can involve several annoying tasks: finding a free parking space, manoeuvring into a narrow space, finding a ticket machine or filling in a prepaid ticket etc. As a result, there is growing interest in parking assistance systems.

There are several techniques, which provide drivers with real-time information on the occupancy of car parks and guide them to the next free parking space. Counting systems like traditional induction loops and video detection [7] as well as secured wireless networks are available in car parks to record entering and existing vehicles. The degree of occupancy (or number of free spaces) is displayed on variable message signs (VMS) and drivers are guided to available parking facilities with directional signs [15]. A recent contribution is "smart parking", which has been implemented in many European and Japanese cities to improve the speed and efficiency of locating, reserving and paying for parking [18]. But even inside a car park assistance may be required to find a free space. There are vision-based systems [13] and wireless sensor networks (WSN), which have been developed and tested, e.g., by Seong-eun et al. [20], Jaeseok et al. [10], Tang et al. [23] and Gongjun et al. [8]. They inform drivers about free parking spaces and route them directly to a free place. 
Many drivers would welcome analogous information services for on-street parking spaces. This task is more difficult, because entries, exits, and parking spaces are less well defined and inappropriate for counting. On-street parking vehicles can be detected with panoramic street images taken with different cameras. Hirahara and Ikeuchi [9] used a laser-ranger finder and a line-scan camera taking epipolar-plane images (EPIs) for this task. This method delivers only static snap-shots. Most attempts to deliver real-time information about parked vehicles on-street rely on roadside sensors. For example, Berenger Vianna et al. [3] as well as Basu and Little [2] developed a system with linked parking meters to find free spaces. Parking meters were equipped with infra-red sensors to identify free and occupied parking spaces; the parking meters were connected with each other via radio frequency transceivers. Free parking meters send their position to the network and passing cars can receive this information as well. BMW developed a similar system in the project 'stadtinfoköln' with about 140 connected parking meters in Cologne [14]. This information service is available for 19 German cities and can be used for free via internet.

Wired sensors networks are impractical to cover large areas that lack a suitable electrical infrastructure because of high deployment and maintenance costs [21]. An alternative option for detecting the occupancy of on-street parking spaces are wireless sensor networks with autonomous sensor nodes [7]. Most of these systems use ultrasonic sensors or induction loops. The devices communicate via radio frequency transmitters; the occupancy information can be accessed through mobile devices [12] or being displayed on VMS. Cenerario et al. [4] took a different path. They employed protocols that vehicles can use to share information by means of $\mathrm{V} 2 \mathrm{~V}$ communication; it could for instance be used to share information about available parking spaces. A similar community-based system is currently tested in Vienna [22]. It enables users to indicate (release) free on-street parking spaces and to find these spaces via a mobile app. This system would however require a high share of market penetration to provide a complete picture, which can only be achieved in the long run.

An accurate detection of on-street parking spaces relies invariably on area-wide infrastructure on street or within vehicles, which causes high costs for implementation and maintenance. Such systems are also controversially discussed, because they aim at navigating drivers as quickly as possible to the next free parking space, that way making car use more convenient. It is commonly accepted that car use should not be further encouraged, in particular not in the inner districts of large cities. This argues for an information system, which informs road users early about the current and forthcoming parking situation at the destination - preferably prior to departure, when there are still more options available to adapt the behaviour.

Many drivers are able to roughly estimate the availability of short-term parking spaces at the destination based on experience. However, situational influences such as holidays, building sites, and special events introduce variability to the parking pressure, what encourages people to try their luck. As a result, parking search traffic amounts to $25 \%$ of total traffic in the inner districts of Vienna [6]. Rye et al. [19] emphasises that managing information about parking availability should be part of demand management. A more reliable forecast of the occupancy could support the use of alternative options (public transport, Park \& Ride, garage at the destination) and reduce parking search traffic at the destination. The selfregulating effect could be reinforced by variable parking fees depending on the demand. Such schemes are already in operation, e.g. in Amsterdam [17].

The city of Vienna offers an SMS payment service for short-term parking fees, which is called "HANDY Parken". More than $40 \%$ of the short-term parking tickets are paid by this means. The success of HANDY Parken in Vienna opens the way for a solution, which is independent from on-street sensors. Each electronic ticket generates information about the duration of the parking process and the approximate location of the vehicle via cell location. The approach is based on the assumption that these data provide a probabilistic indicator for the number of parked vehicles, thereby enabling an estimation of the total occupancy. A real-time readout procedure of position data of HANDY Parken does not exist yet, but has to be developed.

\section{Objectives}

The objective of the research project this article reports on was to develop a real-time model for the occupancy of short-term parking zones, which works without roadside infrastructure, but only uses existing real-time data sources (Fig. 1). Three different kinds of data were tested for their predictive power:

- position data of short term parking customers, who buy an electronic parking ticket on their mobile phone via the HANDY Parken service;

- counts of short-term parking customers in car parks in or close to the target area;

- traffic flow volumes derived from around 300 automatic counting sites in Vienna.

We focussed on these data sources, because they are already available or could be gained at low cost. Moreover, this article is only about (i) testing for the predictive power of these data sources, (ii) developing a suitable model specification, and (iii) evaluating the performance of the model. The development of a physical model is not part of this article. The resulting model shall not exactly map the occupancy of single parking lots, but provide a sufficiently accurate description and reliable prediction of the parking pressure in the target area.

Vienna provides optimal conditions for this attempt due to the high share of mobile phone parkers. Parking meters are not 
Fig. 1 Data flow in the real-time occupancy model

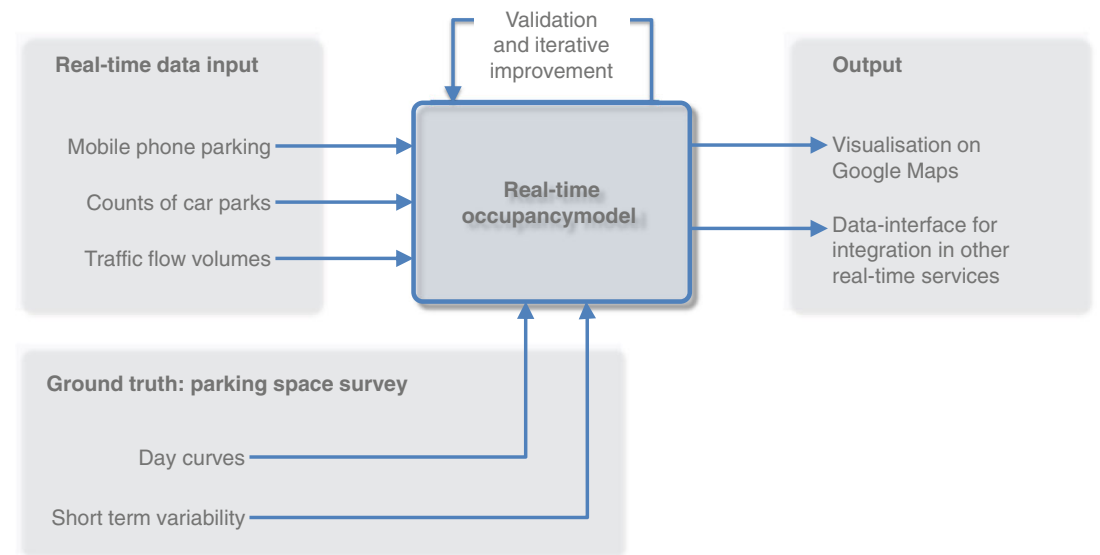

available in Vienna and sending an SMS is apparently considered much more convenient than filling in a paper ticket. As a result, more than $40 \%$ of parking tickets is paid by this service, what corresponds to more than a million SMS tickets every month. This makes HANDY Parken the most commonly used mobile service in Austria.

The mobile phone data are generated only during the validity period of the short-term parking zone and arrive just in time, which limits their usability for a forecast. Therefore, two further real-time data sources were tested in this study, which are available all time and may increase the reliability of forecasts. Both data sources are state of the art, but their use as real-time indicator of the occupancy of short-term parking zones remains to be proven.

The real-time occupancy model was developed and calibrated with data of an empirical parking space survey in two test areas. The most challenging tasks were to find out, (i) if the extraction of position data of HANDY Parken customers is technically and legally feasible and (ii) if the three aforementioned indicators can predict the real-time occupancy of the short term parking zones. The expected result is an online prototype, equipped with a visualisation on Google Maps and a data-interface for integration into existing travel information services. Preliminary results were presented at the ITS World Congress 2012 in Vienna.

\section{Real-Time Data Sources}

The mobile phone parking data constitute the most promising indicator of the occupancy model. The HANDY Parken service has an agreement with several mobile network operators (MNOs), the largest of which participated in the research project. Reading out all SMS-tickets booked in a given time interval together with the permitted parking duration is technically and legally feasible. But, we also need to determine the position of the mobile phone from which the SMS was sent. It serves as proxy for the position of the car and is allocated to a particular street section. We aimed to perform this task by determining the coordinates of the active network cell. This procedure is less precise than GPS location, but can be universally applied, not only on smart phones. Due to the high density of network cells in the inner districts of Vienna, we expect a spatial accuracy of 100-200 m. Given that drives roam areas of a similar size when looking for a parking space, a more precise location is presumably not necessary for an information service about the occupancy of on-street parking spaces.

The Austrian Data Protection law under the rule of the European Data Protection law (EU-Dir. 95/46/EC and EU Dir. 2002/58/EC) [5] as well as the Austrian Telecommunication Act ( $\$ 99$ TKG2003) raise several cautious questions regarding privacy concerns: What kind of data retrieval is permitted for the MNO? At which stage of data processing will the aggregation take place? What level of aggregation is sufficient? These questions could not be answered in advance, but had to be discussed during the project. The data protection officers of the MNO finally decided against a data transfer despite an initial agreement. As a result, the HANDY Parken data could be made available for calibrating the model, but will not be available for operation.

The counts of short-term parkers in the car parks were easier to get, because all car parks in Vienna dispose of automatic counting systems. The counts are periodically retrieved and fed into the Viennese parking guidance and information system. However, for the development of an occupancy model it was necessary to distinguish between customers with long term contracts and short term customers. Since the parking information system requires only the total number of free parking spaces for its operation, this distinction is not common state of practice. We achieved an agreement with five of the six car park operators in the test areas. All of them were able to distinguish between long term and short term parkers and provided the counts during the parking space survey.

Traffic flow data could be collected without any difficulty. They are already collected at a central point, where they feed into a transport model, which is in service at www.AnachB.at. A data exchange protocol has been established, so that we could retrieve the data at any time. 


\section{Parking Space Survey}

The parking space survey conducted in the research project served two purposes: (i) to deliver the 'ground truth' for the calibration and validation of the occupancy model; and (ii) to deliver the day curves of those vehicles, which have a permanent parking permission, any other special permission, or no permission at all (fee dodgers). These parkers leave no electronic trace for real-time indication. The survey was conducted in two test areas as shown in Fig. 3 with a total of 3,000 parking spaces. The areas vary in terms of residents-visitors ratio, supply of on- and off-street parking, spatial functions, and demographic structure. The survey was carried out in three periods in February, March and April 2012. It should be noted that the parking fee had been increased between period 1 and 2 from previously 1.20 to $2.00 € / \mathrm{h}$ (the survey also served to estimate the effect of this intervention), so that only the 2 nd and 3 rd period are suitable for cross-validation under ceteris paribus conditions.

The survey started with a record of all parking supplies. For each available parking space it was indicated, whether it is a regular short term parking space, a special parking space for loading, disabled drivers, or any other specific group. The demand of parking spaces was afterwards observed periodically every $30 \mathrm{~min}$ from 8 am to $10 \mathrm{pm}$. Each parked vehicle was registered along with the type of parking permission in terms of permanent permission, fill-in ticket, or no visible permission. The latter could be fee dodgers or users of the mobile parking service. In order to distinguish between the two, we recorded the license plates of these vehicles and checked them against the HANDY Parken database, which allowed us to determine, which of these cars had a valid electronic ticket during the observation period.

\section{Observed Occupancy Rates}

The cars parking on short-term parking spaces can be grouped into the following categories according to the type of parking permission:

Fig. 2 Share between different types of parking permissions as fractions of the estimated number of available parking spaces in 1 st district (area 1) and 6th district (area 2)
- permanent permission (mainly residents, but also businesses and other specific groups);

- short term permission in terms of a prepaid fill-in ticket;

- short term permission in terms of an electronic ticket; and

- no permission; these are fee dodgers who forgot to buy a ticket or deliberately try their luck that they are not enforced and punished; the share is $12 \%$ in the total sample; it matches well with the experience of the parking surveillance authority.

The repeated observations of parking cars (every $30 \mathrm{~min}$ from 8 am to $10 \mathrm{pm}$ on 11 days) result in $28 \times$ $11=308$ data points in time for each street section. The objective of the occupancy model is to predict the occupancy rate of an area rather than the number of parked cars. We thus translated the car counts into fractions of available parking spaces occupied by different categories as shown in Fig. 3. The result reveals strong differences between the areas (Fig. 2). The share of short-term parkers is approx. $40 \%$ in the city centre (area 1), whereas it is only $20 \%$ in the residential area (area 2). The day curves are also different. The occupancy in the city centre is highest during the day and again during the opening hours of pubs in the evening, whereas the residential area shows the highest occupancy in the morning before the residents leave and in the evening after they are back.

\section{Analysis of Relationships Between Occupancy Rates and Real-Time Data Sources}

This section includes the tests of linear relationships between the three kinds of real-time data and the occupancy of short term parking zones. The tests were performed using correlation coefficients. The results and conclusions presented in the following hold only true for Vienna. We do not have data outside Vienna, so we cannot discuss the applicability for other cities.
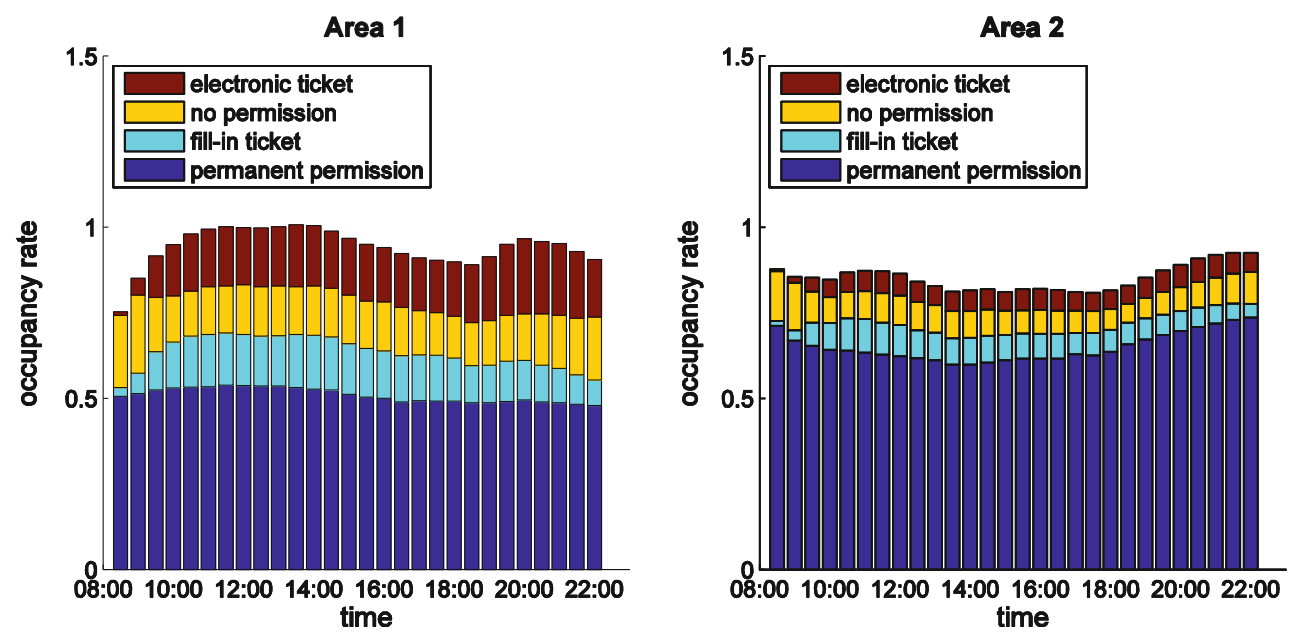


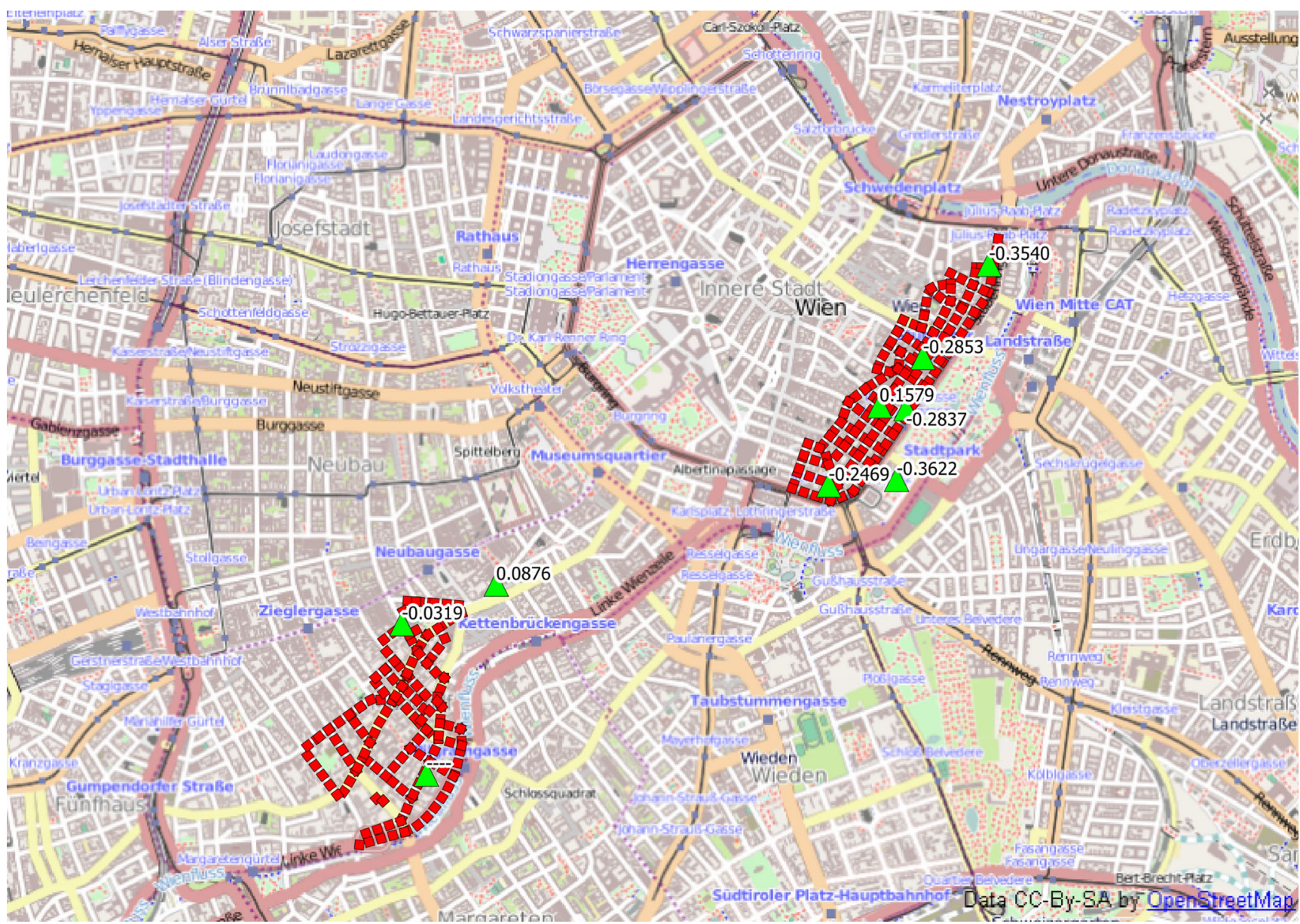

Fig. 3 Correlation coefficients of garage inflow with mean parking occupancy in the corresponding area (right top: 1st district; left bottom: 6th district); red points $=$ street sections, green triangles $=$ car parks,

\subsection{Counts of Short Term Parking Customers in Car Parks}

Car park counts were collected from six car parks in or close to area 1 and three car parks in or close to area 2 (green triangles in Fig. 3). We computed several correlations of car park data with parking space occupancy. As an illustration, Fig. 3 shows the correlations of the inflow of short term parking customers into the car parks with the average parking occupancy of the numbers $=$ correlation between inflow of short term parkers into car parks and on-street parking occupancy

corresponding street sections. We found no systematic relationship between car park inflow and parking space occupancy, so that the former are no suitable indicator of the latter.

Most of the car park operators, who participated in the advisory board of the research project and provided the counts of car park customers, held the view that the garage inflow is just the overflow of on-street parking demand. This view is not confirmed at all by the survey data.

Fig. 4 Correlation coefficients of traffic flow data with mean parking occupancy rates in area 1 (1st district; left graph) and in area 2 (6th district; right graph)
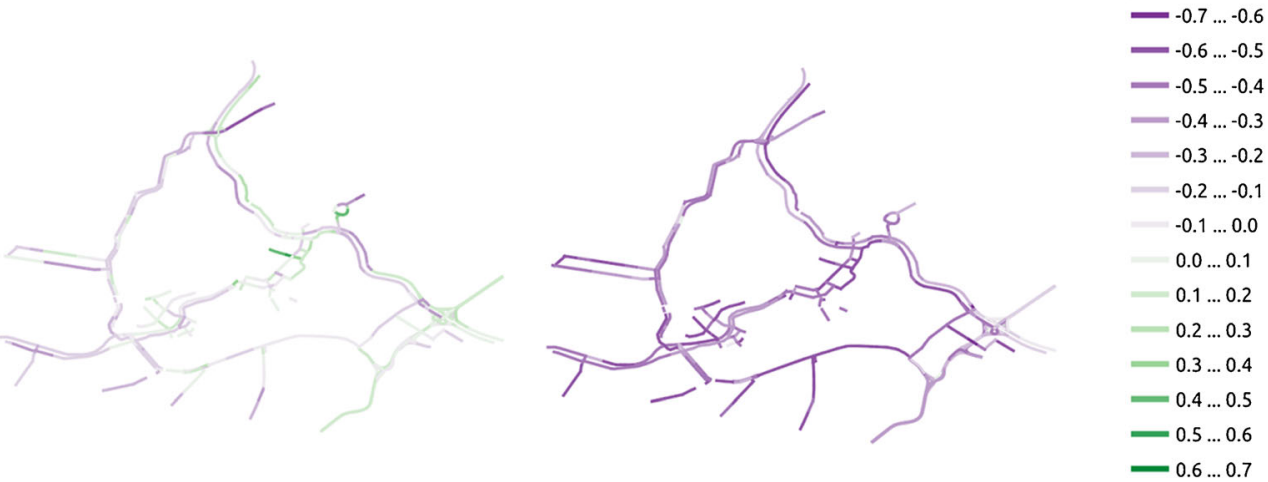
Table 1 Correlation coefficients $(r)$ and significance $(p)$ between electronic parking tickets and other parking permissions in 1st district (area 1) and 6th district (area 2)

\begin{tabular}{|c|c|c|c|c|}
\hline \multirow[t]{2}{*}{ Kind of permission } & \multicolumn{2}{|l|}{ Area 1} & \multicolumn{2}{|l|}{ Area 2} \\
\hline & $r$ & $p$ & $r$ & $p$ \\
\hline Fill-in tickets & 0.515 & 0.000 & 0.503 & 0.000 \\
\hline Permanent permissions & -0.259 & 0.000 & -0.269 & 0.000 \\
\hline Cars without permission & -0.372 & 0.000 & -0.418 & 0.000 \\
\hline All other permissions & -0.067 & 0.241 & -0.238 & 0.000 \\
\hline Total occupancy rate & 0.659 & 0.000 & 0.115 & 0.043 \\
\hline
\end{tabular}

\subsection{Traffic Flow Volumes}

We examined traffic flow data of 830 major roads in the Vienna region. They were derived from a traffic model operated by the provider of real time traffic information in the Vienna reagion [24]. The Model uses the data of some 300 automatic counting sites as input ([11]). In order to test for the predictive power of the traffic flows, we computed correlation coefficients with mean occupancy rates in both target areas. The results are given in Fig. 4. Although we found some large correlations among the numerous candidates, they have different signs and don't reveal any recognisable geographical pattern. We thus considered the relationship between traffic flow data and parking space occupancy too fragile to be used as predictor in the real-time occupancy model.

\subsection{Mobile Phone Parking Data}

These data were the most promising candidates for indicating the occupancy of short term parking zones in real time. Our hypothesis was that (i) mobile phone parkers are a congruent subset of all short term parkers, and that (ii) the latter can be added to the number of permanent parkers, which evolves according to its own day curve independent from short term parkers. The mobile network operator involved in the research project refused to provide the location data of mobile phone parkers for privacy concerns (see Section 3). For the vehicles observed in the parking space survey, however, we could retrieve this information from the HANDY Parken database.

Table 1 shows the correlation coefficients of the number of electronic tickets with other kinds of permissions and with the total occupancy rate; it sheds some light on the relationships between these quantities. The strong positive correlation between electronic tickets and fill-in tickets indicates that mobile phone parkers are indeed a congruent subset of all short term parkers (hypothesis 1). However, the assumption of independence between short term parkers and permanent parkers (hypothesis 2) was rejected. The negative correlation with permanent permissions and fee dodgers (without permission) indicates a displacement effect, which may occur in cases when the total demand exceeds parking space supply.

This pattern appears similar in both areas. A difference between the areas however appears when it comes to the correlation between electronic tickets and total occupancy rate. Area 1 shows a high positive correlation, whereas area 2 shows a low correlation. The reason is the lower share of permanent parkers in area 1. It causes that the relationship between electronic tickets and total occupancy rate is less adversely affected than in area 2.

Figure 5 shows a linear regression $\widehat{o}=k x+d$ of the total occupancy rate $\widehat{o}$ (last row in Table 1) on the percentage $x$ of parking space occupied by cars with electronic tickets. The model explains $r^{2}=43.5 \%$ of the occupancy rate variance in area 1 and only $r^{2}=1.3 \%$ of the variance in area 2 .

\section{Development of the Real-Time Model}

In order to measure the improvement in prediction gained from the real-time information we defined two reference models, which differ in the underlying assumption:

(1) The constant average model is based on the naive assumption that the occupancy rate stays at a constant average level at any time; it neglects the variability throughout the day. The expected average occupancy rate is simply estimated by
Fig. 5 Linear regression of the total occupancy rate on the percentage of parking space occupied by mobile phone parkers in 1st district (area 1) and 6th district (area 2)
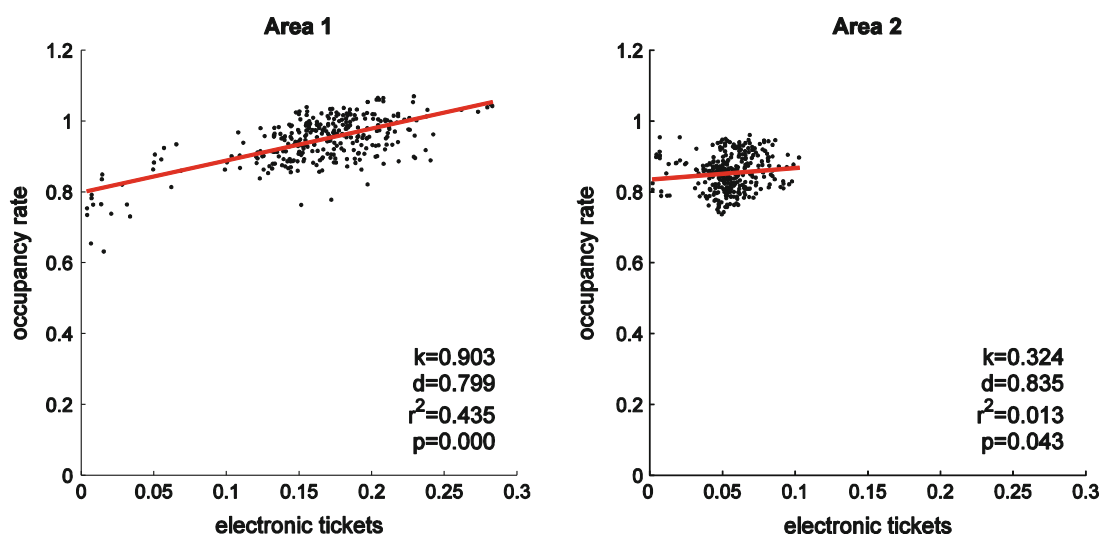
Fig. 6 Linear regression of the residuals of occupancy rate $\widetilde{\mathbf{o}}_{\mathbf{t}, \mathbf{d}}$ on the residuals of the number of mobile phone parkers $\widetilde{\mathbf{p}}_{\mathbf{t}, \mathbf{d}}$ in 1 st district (area 1) and 6th district (area 2)
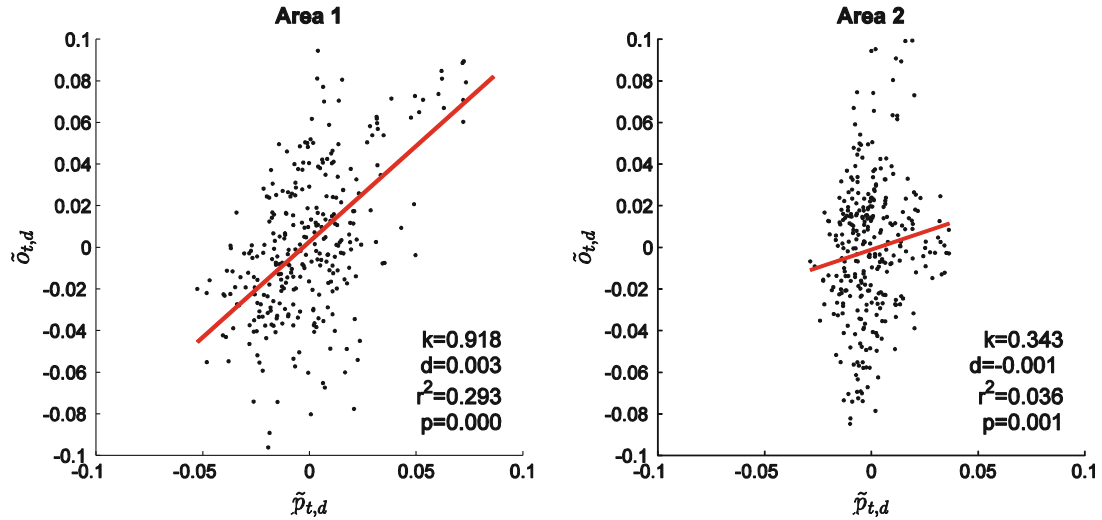

$$
\bar{o}=\frac{1}{D T} \sum_{d} \sum_{t} o_{t, d}
$$

over all days $d$ and time intervals $t$ from a sample of $D$ days each divided into $T$ time intervals. The Root Mean Square Error (RMSE) of this predictor is given by the sample standard deviation

$\mathrm{s}_{o}=\sqrt{\frac{1}{D T} \sum_{d} \sum_{t}\left(o_{t, d}-\bar{o}\right)^{2}}$

(2) The average day curve model is based on the slightly more advanced assumption that the occupancy rate follows the same average day curve on all days. The expected occupancy rate in time interval $t$ on any day is estimated by

$$
\bar{o}_{t}=\frac{1}{D} \sum{ }_{d} o_{t, d}
$$

where $o_{t, d}$ is the occupancy rate on day $d$ in time interval $t$. This model explains $65.8 \%$ of the variance of the occupancy rate in area 1 and $54 \%$ in area 2 , respectively. The resulting day curves are shown in Fig. 2.

We tested the increase of predictive power gained from the real-time information against these models. The car park counts and traffic flow data were excluded from the outset, because no systematic relationship could be identified between these quantities and the parking space occupancy rate

Fig. 7 RMSE of a cross validation of occupancy rate predictions based on an average day curve model without (red line) and with (blue bars) realtime indication of purchased electronic tickets for time intervals $\mathrm{t}+0$ to $\mathrm{t}+3$
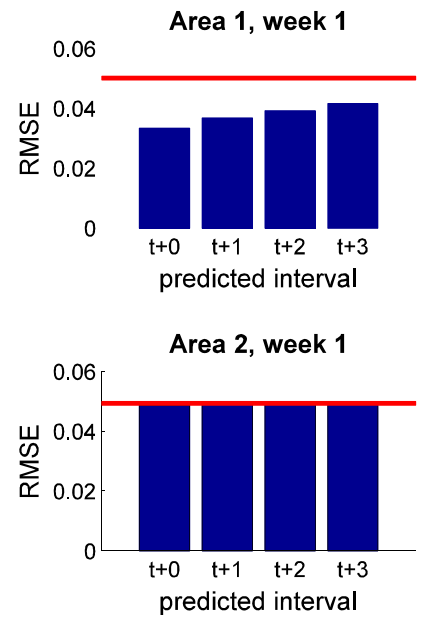

(see chapter 6); only the number of purchased electronic tickets was considered in the model. Predictions based on this indicator explain $43.5 \%$ of occupancy rate variance in area 1 and $1.3 \%$ in area 2 (Fig. 5). This is still inferior to predictions based on the average day curve model, which account for $65.8 \%$ and $54 \%$, respectively (eq. 3). Nonetheless, it is possible that the real-time indicator improves the predictive power, if added to the average day curve model. We tested this possible improvement in three respects:

- improvement of approximation of the occupancy rate in the current time interval;

- improvement of prediction of the occupancy rate of future time intervals;

- improvement of prediction of the occupancy rate in exceptional situations, in which the occupancy rate differs considerably from the usual day curve.

\subsection{Approximation of the Occupancy Rate in the Current} Time Interval

In order to determine the additional variance explained by the real-time indicator, we calculated the residuals of the average day curve model $\widetilde{o}_{t, d}=o_{t, d}-\bar{o}_{t}$ and, analogously, the residuals of the number of purchased electronic tickets $\widetilde{p}_{t, d}=p_{t, d}-\bar{p}_{t}$.
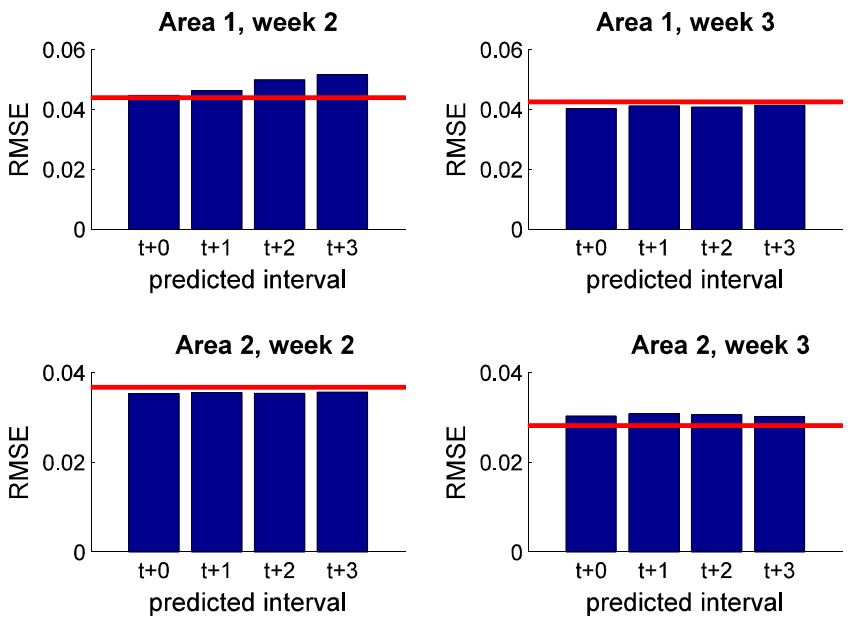
The additional percentage of occupancy rate variance explained by a linear regression model

$\widehat{o}_{t, d}=k \widetilde{p}_{t, d}+d$

is $\mathrm{r}^{2}=29.3 \% \times(1-65.8 \%)=10 \%$ in area 1 and $\mathrm{r}^{2}=3.6 \% \times(1-$ $54 \%)=1.7 \%$ in area 2 , respectively. Figure 6 shows a plot of $\widetilde{\mathrm{p}}_{\mathrm{t}, \mathrm{d}}$ against $\widetilde{\mathrm{o}}_{\mathrm{t}, \mathrm{d}}$ for both areas along with the linear regression model according to eq. (4).

\subsection{Prediction of the Occupancy Rate of Future Time Intervals}

The attempt to improve the prediction of the occupancy rate of a time interval in the near future by means of the number of purchased electronic tickets in previous time intervals is based on a linear model of the day curve of electronic tickets. The model uses the mean values $\bar{p}_{t}$ and the covariance matrix $\mathbf{S}$ of electronic tickets purchased in previous time intervals to compute the predictor

$\widehat{p}_{t+i}=\bar{p}_{t+i}+\mathbf{S}_{t+i ; t-j, \ldots, t} \mathbf{S}_{t-j, \ldots, t ; t-j, \ldots, t}^{-1}\left(p_{t-j, \ldots, t}-\bar{p}_{t-j, \ldots, t}\right)$

of the number of electronic tickets, which will be purchased in time interval $t+i$, given the number of electronic tickets purchased in time intervals $t-j, \ldots, t$. The predictor of the occupancy rate in time interval $t+i$ is again computed by a linear model, which uses the predictor of the number of electronic tickets $\widehat{p}_{t+i}$ as predictor:

$\widehat{o}_{t+i}=\bar{o}_{t+i}+k\left(\widehat{p}_{t+i}-\bar{p}_{t+i}\right)+d$

The model parameters $\mathbf{S}, \bar{p}_{t}, \bar{o}_{t}, k$ and $d$ are estimated from empirical data.

A separate model was developed for both areas and subject to three cross-validation rounds. Within each round, two of the three survey weeks served for calibration, while the remaining week served for validation. In the prediction model given by eq. (6) we chose $j=0$, i.e., only the electronic tickets purchased in the current time interval were used for prediction. Figure 7 shows the Root Mean Square Errors (RMSE) of occupancy rate predictions calculated $0,30,60$ and $90 \mathrm{~min}$ ahead. Each chart shows a separate cross-validation round, which corresponds to one of the three weeks. The red line indicates the RMSE of predictions based on the average day curve model $\widehat{o}_{t+i}=\bar{o}_{t+i}$. The real-time indicator could in most cases not reduce the prediction error of the average day curve model.

A direction for future work would be to examine the prediction accuracy of an implementation in a Kalman filtering framework with measurement model $p_{t}^{*}=h o_{t}^{*}+\epsilon_{t}$ and process model $o_{t+1}^{*}=\mathbf{F}_{\mathbf{t}} o_{t}^{*}+\eta_{t+1}$ with observations $p_{t}^{*}=p_{t}-\bar{p}_{t}$, hidden state variables $o_{t}^{*}=\left(o_{t}-\bar{o}_{t}\right)$, observation model $h=k^{-1}$, observation noise $\epsilon_{t} \sim N\left(0, \sigma_{t}\right)$, state transition model $\mathbf{F}_{\mathbf{t}}=$ $\operatorname{cov}\left(o_{t+1}, o_{t}\right) / \operatorname{var}\left(o_{t}\right)$ and process noise $\eta_{t+1} \sim N\left(0, \xi_{t}\right)$.

\subsection{Prediction of the Occupancy Rate in Exceptional Situations}

Exceptional situations are by definition rare and will hardly come up numerously in three weeks survey period. We identified only one event, in which the occupancy rate differed considerably from the usual level. It was Shrove Tuesday in the 1st week, an event at which particularly many people visit the bars and pubs in the inner district of Vienna (area 1). This situation is included as one of three days in the upper left chart of Fig. 7. In this particular case it turns out that the real-time model predicts the occupancy rate clearly better than the average day curve model. The error improvement is strongest in the current time interval, but it still appears in predictions of
Fig. 8 Internet information tool based on the real-time model

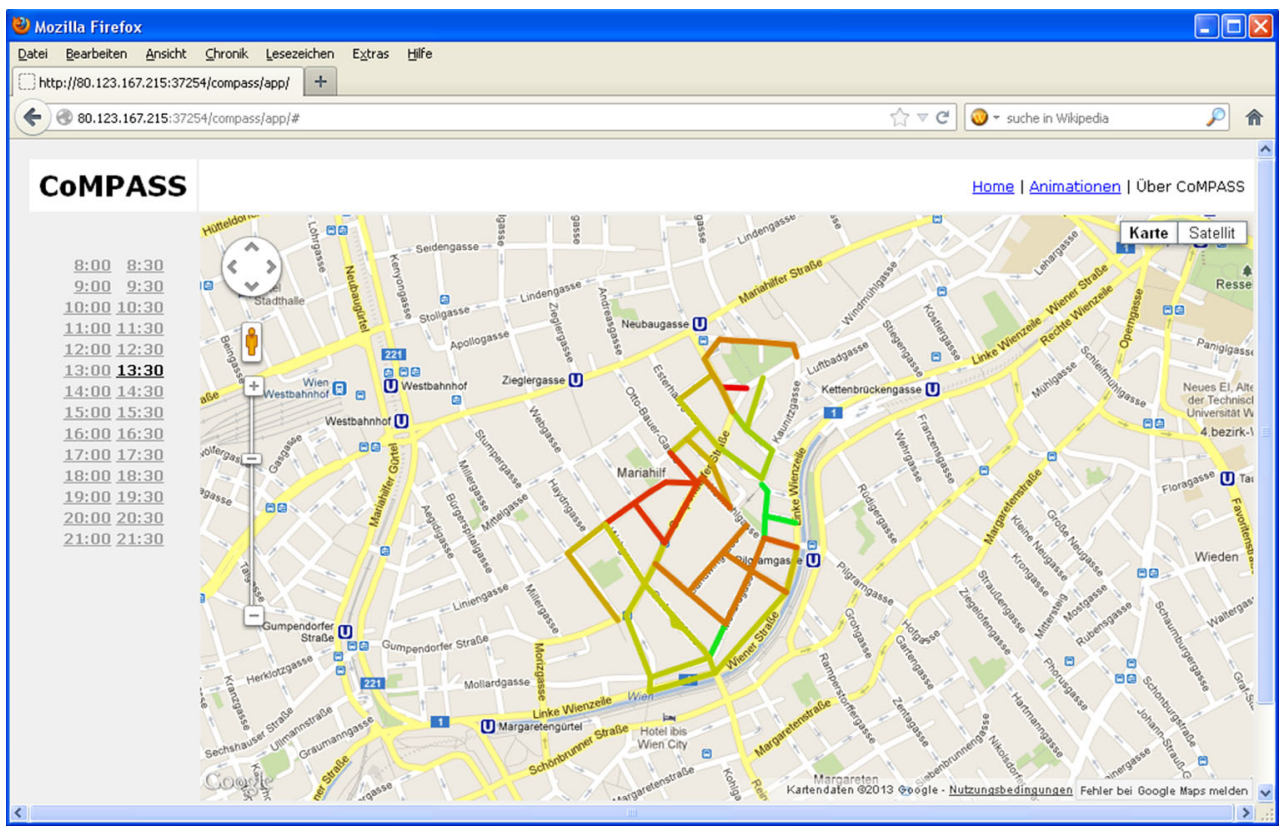


future time intervals. This result indicates that the real-time information about electronic parking tickets might increase the accuracy of an occupancy model in situations, in which the demand of parking place deviates from the usual level.

\section{Conclusions and Outlook to Model Application}

We developed and tested a real-time occupancy model of short-term parking zones, which works without roadside infrastructure, but only uses existing real-time data sources. The following lessons we have learned from our work:

- Among the tested real-time data sources (electronic parking tickets, counts of car parks, traffic flow data) only the number and location of electronic tickets is able to indicate the occupancy rate in a given time interval and street section. However, this indicator is not yet available due to privacy concerns of the major mobile network operator in Austria.

- The occupancy rate of on-street parking spaces follows a strongly recurrent pattern on different days. An average day curve model thus predicts the occupancy at a given time interval very well. For the usual day-to-day variations of the occupancy rate it can hardly be outperformed by a real-time model.

- Unusual deviations from the day curve due to exceptional events are better predicted (and can only be predicted) by the real-time model. We had only one exceptional event in our three weeks survey, but such events will occur more often in the long run. There are various factors that significantly influence human behaviour: holidays, day characteristics such as working day, weekend, day before or after holiday or weekend, big events, etc. This makes such a model very useful. Its further development requires data from longer periods. It is not necessary to anticipate the exceptional events; they would simply appear in the real-time signal, so that the model can learn from its own history for future events.

The unavailability of the location data of electronic parking tickets is not necessarily the end of the story. The negative decision was based on an extremely narrow interpretation of the legal regulations, so that we see a chance for a positive decision in a second attempt. A significant improvement can also be expected from the new standards for Intelligent Transport Services (ITS) and their subsection Cooperative IT, which are currently developed by the standard organisations ISO, CEN, and ETSI. The new standards will start at 2016 with the availability of new cars. The solution will be a combination of GPS-data, vehicle to vehicle (V2V) and vehicle to infrastructure (V2I and I2V) communication. They will deliver location data in the range of five meters. It can be used as real-time indicator of parked vehicles with unreached accuracy (among many other things).
A simple option to make the information service available to the users would be a stand-alone webpage as shown in Fig. 8, where the user can chose the area and time for which the occupancy information shall be provided. The main goal is however to integrate the service into existing information services, e.g.

- the intermodal real-time traffic service AnachB.at;

- the mobile payment service HANDY Parken;

- the Viennese parking guidance system;

- traffic information services of broadcasting stations.

The end users' benefit of the information service is in either case a better knowledge of the current and forthcoming occupancy of on-street parking spaces at the destination. It could also include recommendations for alternative options in case of high parking pressure such as off-street parking facilities, intermodal transport, or public transport.

Acknowledgments Funding for this project is provided by the Federal Ministry for Transport, Innovation and Technology represented by the Austrian Research Promotion Agency (FFG).

Open Access This article is distributed under the terms of the Creative Commons Attribution License which permits any use, distribution, and reproduction in any medium, provided the original author(s) and the source are credited.

\section{References}

1. Ando, R., Mimura, Y.: A study to develop an information providing system on travel time. Int. J. Intell. Transp. Syst. Res. 8(2), 77-84 (2010)

2. Basu, P., Little, T.D.C.: Wireless Ad Hoc Discovery of Parking Meters, Multimedia Communications Laboratory (MCL) Technical Report No. 01-08-2004 (2004)

3. Berenger Vianna, M.M., Da Silva Portugal, L., Balassiano, R.: Intelligent transportation systems and parking management: implementation potential in a Brazilian city. CITIES 21(2), 137-148 (2004)

4. Cenerario, N., Delot, T., Ilarri, S.: A content-based dissemination protocol for VANETs: exploiting the encounter probability. IEEE Trans. Intell. Transp. Syst. 12(3), 771-782 (2011)

5. Directive 95/46/EC of the European Parliament and of the Council of 24 October 1995 on the protection of individuals with regard to the processing of personal data and on the free movement of such data.

6. Dorner, A., Herry, M., Schuster, M.: Parkraumbewirtschaftung in Wien (Parking space management in Vienna). Werkstattbericht der Stadtplanung Wien, Magistratsabteilung 18, Vienna, Austria (1997)

7. Federal Highway Administration: Advanced Parking Management Systems: A Cross-Cutting Study. U.S. Department of Transportation, Washington (2007)

8. Gongjun, Y., Weiming, Y., Rawat, D.B., Olariu, S.: SmartParking: a secure and intelligent parking system. IEEE Intell. Transp. Syst. Mag. 3(1), 18-30 (2011)

9. Hirahara, K., Ikeuchi, K.: Detection of street-parking vehicles from panoramic street image, Proceedings Intelligent Transportation Systems, IEEE, 12-15 October 2003, 2:993-998 (2003)

10. Jaeseok, K., Haeyong K., Jongsoo, J., Yongbin, S., Pyeongsoo M.: Field Deployment of a Large-Scale WSN for Parking Management System, Sensor Mesh and Ad Hoc Communications and Networks (SECON), 7th Annual IEEE Communications Society Conference, 21-25 June 2010, pp. 1-3 (2010) 
11. Käfer, A., Fürst, B., Pediaditis, E., Gabert, K.: Straßenverkehrszählung Wien 2010. Auswertung Gemeindestraße A + B (Road traffic census Vienna 2010. Analysis of communal roads A + B). Magistrat der Stadt Wien, Magistratsabteilung 18, Vienna, Austria (2001)

12. Markoff, J.: Can't Find a Parking Spot? Check Smartphone, Online: http://www.nytimes.com/2008/07/12/business/12newpark.html?_r= 2\&ref=business\&oref=slogin\&oref=slogin (10.01.2012) (2008)

13. Micheloni, C., Foresti, G.L., Snidaro, L.: A network of co-operative cameras for visual surveillance. Vision Image Signal Proc. 152(2), 205-212 (2005)

14. Motor-Talk: Nie mehr Parkplatzsuche: Persönlichen Stellplatz online reservieren, (Never searching a parking space again: reserve a parking space online), Online: http://www.motor-talk.de/news/niemehr-parkplatzsuche-persoenlichen-stellplatz-online-reservierent18460.html (10.01.2012) (2002)

15. Orski, K.: Best space scenario. Traffic Technol. Int. 2003, 54-56 (2003)

16. Pellecchia, A., Igel, C., Edelbrunner, J., Schoner, G.: Making driver modeling attractive. IEEE Intell. Syst. 20(2), 8-12 (2005)

17. Riedel, R.: Parkraumbewirtschaftung in Amsterdam NL (Parking Space Management in Amsterdam NL), Stadtplanung Wien, Magistratsabteilung 18 - Stadtentwicklung und Stadtplanung (2006)

18. Rodier, C., Shaheen, S., Eaken, A. M.: Transit-Based Smart Parking in the San Francisco Bay Area, California - Assessment of User Demand and Behavioral Effects. Transportation Research Record: Journal of the Transportation Research Board, No. 1927, pp. 167-173. Transportation Research Board of the Acadamies, Wanshington, D.C. (2005)

19. Rye, T., Hunton, K., Ison, S., Kocak, N.: The role of market research and consultation in developing parking policy. Transp. Policy 15(6), 387-394 (2008)

20. Seong-eun, Y., Poh, K. C., Taehong, K., Jonggu, K., Daeyoung, K., Changsub, S., Kyungbok, S., Byungtae, J.: PGS: Parking Guidance System Based on Wireless Sensor Network, pp. 218-222. Wireless Pervasive Computing, ISWPC 2008, 3rd International Symposium, 7-9 May 2008 (2008).

21. Sifuentes, E., Casas, O., Pallas-Areny, R.: Wireless magnetic sensor node for vehicle detection with optical wake-up. IEEE Sensors J 11(8), 1669-1676 (2011)

22. Sofortparken.at: http://www.sofortparken.at; retrieved at March 08 2013 (2013)

23. Tang, V.W.S., Zheng. Y., Cao, J.: An Intelligent Car Park Management System Based on Wireless Sensor Networks, pp. 65-70. Pervasive Computing and Applications, 1st International Symposium, 3-5 August 2006 (2006)

24. Unterluggauer, A.: AnachB - die neue Live-Verkehrsinformation der Vienna Region (AnachB - The New Live Travel Information in the Vienna Region). Paper presented at the AGIT 2009 Symposium und Fachmesse für Angewandte Geoinformatik, Salzburg, Austria (2009)

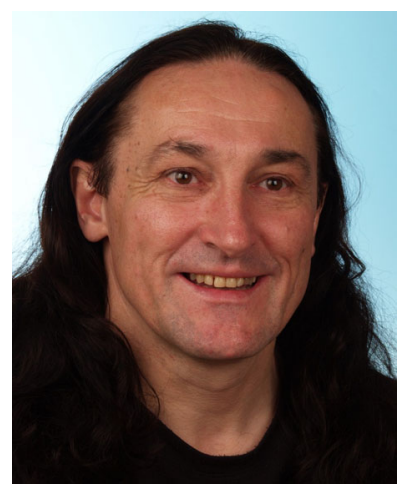

Reinhard Hössinger was born in Vienna in 1963 and he studied biology and ecology. Since 2000 he is research assistant in the institute for transport studies at the University of Natural Resources and Life Science Vienna. He is expert in travel behaviour research with particular focus on discrete choice analyses including includes the conduction of discrete choice surveys and data analysis using advanced statistical procedures such as discrete choice modelling and structural equation modelling.

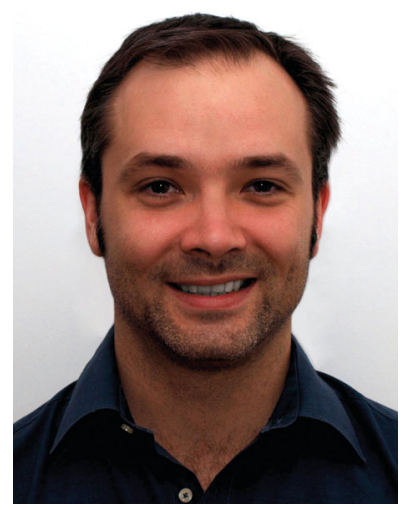

Peter Widhalm, born in 1978, holds a Master's Degree in Computer Science from the Vienna University of Technology. From 1999 to 2009 he worked as a software architect and lead developer in $\mathrm{R} \& \mathrm{D}$ projects, where he was responsible for the development of novel GIS-applications and enterprise release management tools. Since 2009 Peter has been working as a researcher at the Dynamic Transportation Systems team of AIT Mobility and mainly focuses on acquisition and analysis of mobility data with machine learning methods. Peter also manages research projects in the areas of travel demand modeling and traffic telematics.

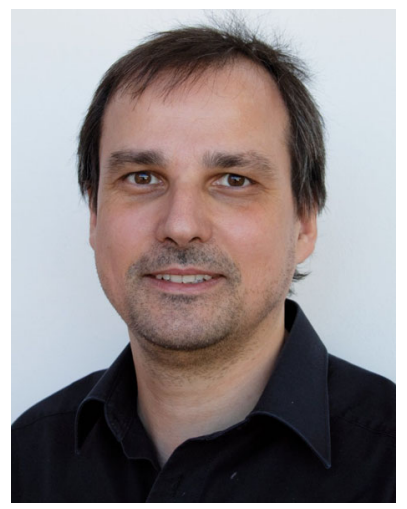

Michael Ulm, born in 1967, studied mathematics at the Université du France-Comté Besançon in France and the University of Graz (MSc 1994). He received his $\mathrm{PhD}$ in mathematics from Ulm University in 1997. Michael worked as a research assistant at Joanneum Research (1991-95), Ulm University (1995-1998) and Rostock University (1998-2004). From 2004 to 2009 he was researcher at the ISIS Papyrus Ges.m.b.H. focusing on the development of AI algorithms for documents analysis as well as application development in $\mathrm{C}++$ and GUI programming. Michael joined the Dynamic Transportation Systems team at AIT Mobility in 2010, where he is responsible for the development of efficient traffic flow algorithms in $\mathrm{C}++$.

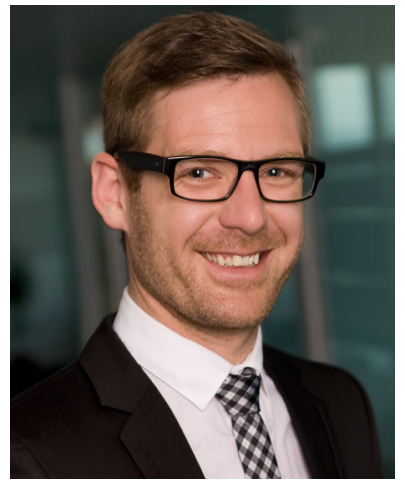

Klaus Heimbuchner has more than 12 years experience in project development and communication especially concerning infrastructure, traffic and ITS projects. After studying traffic engineering at the Vienna University of Technology Heimbuchner worked as spokesman for the Vienna city council for traffic and city development. Since 2007 Heimbuchner works as self employed consultant for marketing and technology focused on Intelligent Transport Systems. 


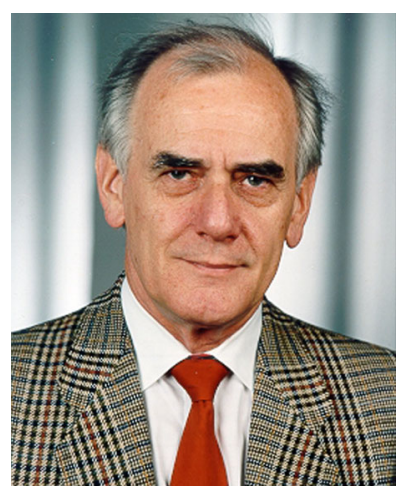

Eike Wolf was born in Vienna in 1941. He has a professional education as telecommunication engineer and he studied law at University of Vienna 1973 - 1978. As a technician he is involved in research and development projects for telecommunication. $\mathrm{He}$ is an industrial counselor for industrial and planning companies and since 1996 he is an independent management consultant. $\mathrm{He}$ is giving lectures at three universities for applied Sciences in Austria. Furthermore he is the chairman for ITS standardization in ASI 2004 - 20011 and a EuroPriSe certified legal expert for data protection.

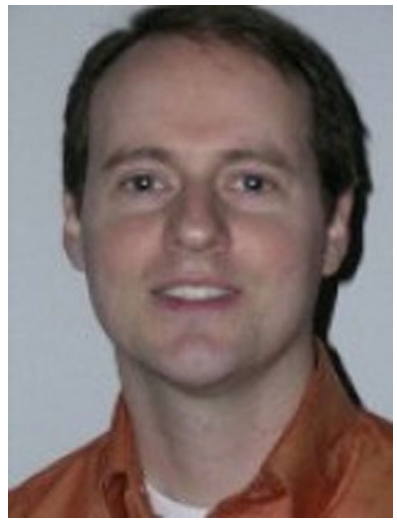

Roland Apel was born in Vienna in 1972. After receiving education in Electrical Engineering and Computer Science he focused on $\mathrm{m}$-commerce and mobile solutions. As practitioner and entrepreneur he was involved in all relevant Austrian m-commerce solutions. He is married and father of two children.

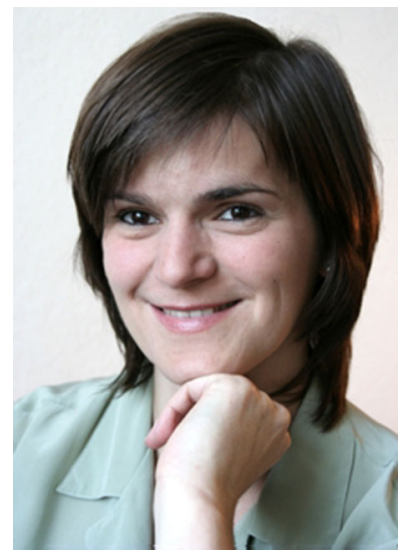

Tina Uhlmann was born in Leipzig (Germany) in 1981. She studied geography as well as transport and landscape planning at the Technical University of Dresden (Germany). Ms. Uhlmann is experienced in traffic surveys and she has in-depth knowledge in the field of sustainable urban transport measures. After here studies she worked in the Joint Technical Secretariat of the INTERREG IIIB Programme CADSES in the field of public relations where. Since May 2008 she is a researcher at the Institute of Transport Studies dealing with different national and international projects. 